lus of inhaled methacholine and also non-allergic substances was probably a distinguishing characteristic between asthmatic and control populations.

The relation of bronchial hyperreactivity to allergy is not fully understood. Whether it occurs independently of allergy, is secondary to it, or is often associated with it is unknown. The evidence suggests that probably it is independent of allergy and that it may well he an associated basic disorder in all asthmatic children, the nature of which is at present unknown. In order to define the roles and relation of allergy and bronchial hyperreactivity in asthma a longitudinal population study will be necessary.

This work was partly supported by a grant from the Asthma Foundation of Victoria.

\section{References}

Blackhall, M. I. (1970). Archives of Disease in Childhood, 45, 363.
Cade, J. F., and Pain, M. C. F. (1971). Australian and New Zealand fournal of Medicine, 1,22 .

Freeman, M. (1969). Australian Paediatric fournal, 5, 133.

Gell, P. G. H., and Coombs, R. R. A. (1968). Clinical Aspects of Immunology,

2nd edn. Oxford, Blackwell.
Hogarth-Scott, R. S., Howlett, B. J., McNicol, K. N., Simons, M. J., and Williams, H. E. (1971). Clinical and Experimental Immunology, 9, 571 .

Hogarth-Scott, McNicol, K. N., R. S., Williams, H. E., and Johansson, S. G. D. (1973). Medical fournal of Australia. 1, 1293.

S. G. D. (1973). Medical fournal of Australia. 1, 1293.
Horn, M. E. C., and Gregg, I. (1973). Chest, 63, Supp., p. 44.

Horn, M. E. C., and Gregg, I. (1973). Chest, 63, Supp., p. 44.
Ishizaka, K., and Ishizaka, T. (1970). Annals of Allergy, 28, 189.

Ishizaka, K., and Ishizaka, T. (1970). Annals of Allergy, 28, 189.

Jones, R. H. T., and Jones, R. S. (1966). British Medical fournal, 2, 976. Childhood, 47, 578 .

Luparello, T., Lyons, H. A., Bleecker, E. R., and McFadden, E. R. (1968). Psychosomatic Medicine, 30, 819.

McIntosh, H., et al. (1972). Journal of Allergy and Clinical Immunology, 49, 131 .

McNicol, K. N. (1971). M.D. thesis, University of Melbourne.

McNicol, K. N., and Williams, H. E. (1973a). British Medical fournal, 4, T. Mikol, C., Renoux, M., and Merklen, F. P. (1961). Bulletins et Mémoires de la Société Médicale des Hôpitaux de Paris, 77, 441.

Parrot, J. L., Laborde-Burtin, C., and Saindelle, A. (1964). Annals of Allergy, 22, 511.

Stenuis, B., Wide, L., Seymour, W. M., Holford-Stevens, V., and Pepys, J. (1971). Clinical Allergy, 1, 37.

Vries, K., et al. (1964). In Bronchitis, Second International Symposium, ed. N. G. M. Orie and H. J. Sluiter, p. 167. Assen, Royal Vangorcum.

Williams, H. E., and McNicol, K. N. (1969). British Medical fournal, 4, 321.

\title{
Spectrum of Asthma in Children-III, Psychological and Social Components
}

\author{
K. N. McNiCHOL, H. E. WILliaMS, J. ALLAN, I. MCANDREW
}

British Medical fournal, 1973,4, 16-20

\begin{abstract}
Summary
Behavioural disturbances in the child, the mother-child and family relationships, and the family social structure were studied in a representative sample of the whole range of asthmatic children and compared with a control group of normal children. Behavioural disturbances occurred more often and at a statistically significant level only in the small group of children with severe and continuing asthma. These children were those with severe chronic airways obstruction as assessed physiologically and also with the most severe allergic manifestations.

Predominant in the mother-child relations was an over-concern to protect the child's health in those children with continuing asthma at 14 years of age. The families of the very severely affected group of children showed evidence of more stress than other families. Socioeconomic conditions were not significantly different in any group of asthmatic children compared with the control group.
\end{abstract}

\section{Introduction}

Clinicians have long known that emotional stress may either precipitate or aggravate attacks of asthma. Much research in

Clinical Research Unit, Royal Children's Hospital, Melbourne, Australia

K. N. McNICOL, M.D., Research Fellow

H. E. WILLIAMS, M.D., P.R.A.C.P., Director

H. ALLAN, S.R.N., DIP. Soc. STuD, Medical Social Worker

I. MCANDREW, B.A., DIP. Soc. STUD., Medical Social Worker asthma in children has been directed to the child's personality, parent-child interaction, parental attitudes to the child, and the relation of emotional disturbance to asthma. Asthmatic children have been reported to show a variety of the following characteristics: anxiety, immaturity, lack of self-confidence, dependency, latent aggression, depression, and egocentricity (Rogerson et al., 1935; Gunnarson, 1950; Mansmann, 1952; Creak and Stephens, 1958; Alcock, 1960).

The most commonly accepted hypothesis is that central to the mother-child interaction is a dependency conflict, asthma being precipitated or aggravated by threat of separation (French and Alexander, 1941). Studies of parental attitudes to asthmatic children have indicated a range of attitudes from rejection to over-protection. Miller and Baruch (1948) found that most of the mothers rejected their child. Rees (1956) and Pinkerton (1967) found over-protection more common, while some parents were ambivalent in their attitudes. Rees (1956) also found that a significantly higher number of asthmatic children had an unsatisfactory family life compared to a control group of normal children. There was less stability, security, warmth and affection, and encouragement.

Review of the literature indicates that knowledge of the emotional disturbances and their prevalence in asthmatic children is limited and that there are conflicting views over important questions. It is uncertain whether the disturbances are peculiar to asthma. There are also differences of opinion on whether emotional disturbance is an aetiological factor in asthma or whether it is a sequel.

The main reasons for these differing opinions and deficiencies in knowledge are the wide variations in the aims and methodology of the studies. Few have a sound epidemiological basis, too often the children studied have been from highly selected groups of asthmatics, controls have been lacking, and the clinical, physiological, and allergic state of the patients undefined. Comparisons are therefore impossible. Many have been critically reviewed (Freeman et al., 1964; Feingold et al., 1966).

The present study aimed to determine (i) whether behavioural 
disturbances are more common in asthmatic than control children; (2) whether all or only some groups of asthmatic children are affected; (3) whether there is any correlation between behavioural disturbances and the severity of asthma as assessed by the clinical, physiological, and allergic status; (4) the characteristics of the disturbances; (5) the parental attitudes to the child; (6) the social structure and function of the families.

\section{Subjects and Methods}

The children studied were the asthmatic and control subjects from the epidemiological study of asthma in Melbourne schoolchildren who were followed from 7 to 14 years of age. The asthmatic children were a representative sample of all wheezing children, including those with minimal symptoms. The method of sampling and the clinical, physiological, and allergic characteristics of these children up to 10 years of age have been described by Williams and McNicol (1969), and up to 14 years of age in the first and second of these three papers ( $\mathrm{McNicol}$ and Williams, $1973 \mathrm{a}$; $1973 \mathrm{~b}$ ).

Aspects of the child's behaviour, mother-child interaction, family relationships, and the social structure of the family were recorded on numerical scales in a form suitable for electronic data processing. Observations were made on the basis of interviews with the mother and child by two medical social workers (J. A. and I. McA.) at 7, 10, and 14 years of age and on clinical examination and interview with the mother by $\mathrm{K}$. McN. at 10 and 14 years of age. Standardized questionnaires relating to specific aspects of the child's school behaviour were answered by the child's teacher at 7,10 , and 14 years of age.

The interviews at 7 and 10 years of age were relatively unstructured. Information about the child's life story and setting was obtained from as many sources as possible, and different aspects were scored on five-point scales. Scoring was difficult because of the subjective nature of some of the personality and behavioural assessments, which were often too general and sometimes based on inference. More objective methods of interviewing and coding were used at the examination at 14 years of age. Some of these coding scales are described in part with the presentation of the findings. Of the several hundred items recorded mainly those in which significant differences were found between the different grades of asthma and the controls are presented. Unless stated the findings are from assessments made at 14 years of age.

\section{Results}

CHILD'S DEVELOPMENT AND BEHAVIOUR

The main aspects of the asthmatic children's development and

Aspects of Child's Behaviour. Comparison of Four Asthmatic Grades with Controls

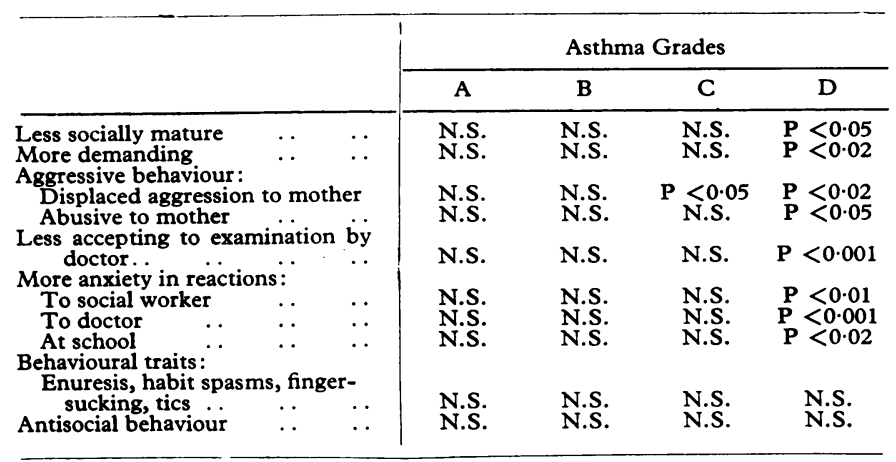

N.S. = No significant difference from controls. behaviour compared with those of the control children are summarized in the table.

Social Maturity.-Social maturity was assessed by scoring the child's capacity to undertake responsibility for various aspects of personal care, household duties, and social activities, as reported by the mother. Grade $\mathrm{D}$ children were the least socially mature, and were the only ones who differed significantly from the controls $(P<0.05)$. In each of the asthma grades the proportion of children who reached the maximum score was less than in the control group.

Demanding Behaviour.-The frequency and intensity of demands for material possessions that the child made of both parents and the need to obtain the mother's attention under certain circumstances were scored separately. Grade D children differed significantly from the control group in demanding material possessions $(P<0.02)$ and from grade $A$ children in demanding mother's attention $(P<0.02)$.

Aggressive Behaviour.-Three areas where aggressive reactions could occur were studied. (1) The mother's report of the child's behaviour when denied something by her or when asked to help in some way was coded separately for the most common type of verbal and physical responses. The five-point coding scales in each case ranged from direct abuse or physical aggression to the mother through displaced aggressive responses to fully-accepting behaviour. The frequency of both the direct and displaced aggressive reactions was also recorded. (2) The child's most common mode of behaviour to the doctor during physical examination was assessed as well as his reactions to the most stressful part, usually venipuncture, using similar five-point scales. (3) The school teacher reported on the frequency of verbal outbursts, minimal physical aggression, fighting, bullying, and destruction of possessions coded on three-point scales of never, occasionally, and frequently. There were no significant differences between the groups in the most common type of physically aggressive behaviour to the mother. Grades $C$ and D children, however, reacted more often to the mother's requests or directions by displaced physical aggression (grade C P $<0.05$ and grade $D P<0.02)$. Grade $D$ children were also the most often abusive to their mothers $(P<0.05)$. During clinical examination grade D children were less accepting of venipuncture or other stressful situations $(P<0.05)$ and protested verbally about them $(P<0.001)$. At school there were no significant differences in the incidence of fighting, bullying, destructive behaviour, or verbal outbursts, though a higher proportion of grade A children were occassionally aggressive in class $(P<0.05)$.

Anxiety.-Anxiety was assessed at the clinical examination and interview by recording the child's physical behaviour, on a scale ranging from constant physical hyperactivity to passivity; his verbal behaviour, from constant irrational, fearful queries to no questions and no verbal concern; and his physiological responses-for example, fainting, pallor, flushing, tears, or involuntary micturition. The teacher recorded whether he was restless in the classroom or a worrier. Only grade D children were significantly different from the control group. They were more restless in interview with the social worker $(P<0.01)$ and with the doctor $(P<0.05)$, and during the clinical examination showed more verbal concern by constantly asking questions and seeking explanations and reassurance $(P<0.001)$. The teachers also reported that grade $\mathrm{D}$ children worried more compared with grade $A$ children $(P<0.02)$. No significant differences in physiological responses were observed between the grades during clincal examination or interviews.

Behavioural Traits.-No significant differences were found between the groups in the prevalence of enuresis, encopresis, finger-sucking, stammering, or tics and nervous spasms from starting school to 14 years of age.

Antisocial Behaviour.-Antisocial behaviour such as stealing and truancy, as reported by either mother or school teacher, was not significantly different in any of the grades of asthmatic children compared to the controls. 


\section{MOTHER'S BEHAVIOUR AND ATTITUDE TO CHILD}

Indulgence.-This was rated by the amount of consideration the child received from the mother compared to other members of the family in relation to material objects and whether her attitudes and decisions for the family were unduly biased in favour of the child. No significant differences between the grades were found in either.

Protection.-The mother's concern to protect the child was coded in respect of his health, his physical security, and his social activities. Mothers of grades $C$ and D children were far more concerned about the child's health than the mothers of control children ( $P<0.001)$. Mothers of grade $A$ children were more concerned with their child's physical security $(P<0.05)$ No differences were found in any grade in concern for the child's social activities.

Limit Setting. - The mother's control over the child's health, physical security, and social activities was noted on a scale ranging from excessively restrictive to completely permissive. Mothers of grades $\mathrm{A}, \mathrm{C}$, and D children were restrictive but only in grade A were they significantly more so than the control mothers, ( $P<0.01$ ).

Reaction to Child's Eating Habits.-The interaction of mother and child at meal times was noted according to whether the child ate without fuss, whether he protested, and whether the mother ignored his behaviour, vacillated in her attitude, or cooked especially for him. Only mothers of grade D children, were involved in conflicts over meals compared with mothers of controls $(P<0.01)$.

Approval.-The mother's presentation of the child during the interview with the social worker was assessed according to whether she condoned or criticized his actions regardless of the appropriateness. Mothers of grade A children were significantly more approving than those of either grade $\mathrm{D}$ or control children $(P<0.05)$. Mothers of grade $D$ children were the most disapproving but not significantly so compared with mothers of controls.

Interest in School Progress.-No significant differences were found between any of the groups in the interest that the mothers showed in the children's progress at school.

\section{MOTHER'S BEHAVIOUR AT INTERVIEW}

The mother was rated on a five-point scale during the interview by both the social worker and the doctor according to her verbal spontaneity, frankness, restlessness, mood (ranging from levity to despondency), and any physiological responses-for example, tears, flushing, or tremor.

No significant differences were found among the mothers in their spontaneity, frankness, restlessness, or mood in the interview with the social workers. But more flushing was observed in mothers of grade $\mathrm{D}$ children by both the social workers and medical officer ( $P<0.01)$ than in mothers of grade $A$ and control children. During the clinical interview the mothers of all grades of asthmatic children were significantly more restless and serious than the mothers of controls, and mothers of grades $C$ and $\mathrm{D}$ children were also more spontaneous, answering extensively and often needing to be redirected in discussion $(P<0.01$ and $<0.05$ respectively.)

\section{FAMILY STRUCTURE}

The ages of the parents; whether they were natural, adoptive, or other substitute parents; and whether any changes or losses of parents had occurred were recorded as well as the birth order of the children and aspects of the health of all members of the family.

There were no significant differences in the ages of the parents or in the birth order of the children in any of the grades of asthma or the controls. However, the families of grade $\mathrm{D}$ children were larger than the families of the grade $A$ children $(P<0.01)$. At the examination at 10 years a higher proportion of the most severely affected asthmatic children were from families in which there had been changes or loss of a parent, mostly fathers $(P<0.01)$. At the examination at 14 years this trend was less than statistically significant in grade $D$ because many of the disrupted families were among those who could not then be contacted. No significant differences occurred in the incidence of psychiatric, neurotic, or other chronic illness in parents and other members of the family.

\section{PARENTAL AND FAMILY RELATIONS}

The following aspects of parental and family relations were recorded from interviews with the mother.

Resentment.-Resentment between parents was found more often in those of grades B and D children $(P<0.05$ and $<0.01$ respectively).

Dominance.-No differences in the decision-making role of each parent were found between any of the asthma or control groups.

Economic Management.-Fewer fathers of grade D children took responsibility for the family's economic management or shared it with the mothers compared with the control group $(\mathbf{P}<0.01)$.

Child Rearing.-Fathers of the grade A children-those who had not had asthma for some years-took the least interest and gave the least support to the mothers in rearing the children ( $\mathbf{P}<0.01$ ).

Mother's Main Source of Support.-The mothers of children in all the asthma groups were less self-reliant but seldom turned to the father for support. Usually they sought it from their own or their husband's family or sources outside $(P<0.05$ compared with controls).

Family Interaction.-Study of the sharing of activities and conflict between members of families showed a trend for the families of grade $D$ children to have fewer joint activities. Families of grade $A$ children were the most argumentative and likely to act out ( $P<0.01$ compared with controls).

\section{SOCIO ECONOMIC FACTORS}

No significant differences were found among the asthmatic and the control groups in the adequacy of housing, home ownership or degree of crowding, the father's occupation, the income available per dependent member of the family, the incidence and duration of unemployment of the father, or the amount of time that either the father or mother spent away from the family at work or in social activities. The fathers of grades $B$ and $C$ asthmatic children, however, changed their employment significantly more than the fathers of control children $(P<0.01$ for both), the change usually being associated with promotion or other improvement in employment.

\section{Discussion}

\section{BEHAVIOURAL DISTURBANCES}

The most important findings were that behavioural disturbances were uncommon in asthmatic children, that they occurred predominantly in the group with severe continuing asthma, and that these children were those with the most severe airways obstruction, pulmonary hyperinflation, and allergic manifestations.

There have been few epidemiological studies of behavioural disturbances in asthmatic children. Graham et al. (1967 reported that behavioural disturbances occurred in 9-, 10-, and 
11-year-old asthmatic children only slightly more often than in other children. In the present study only grade D children showed a significantly greater prevalence of disturbed behaviour than the controls. Grade D children represent 1 in 40 of all wheezy children.

The frequency of behavioural disturbance in asthmatic children has probably been unduly emphasized. Investigations have almost always been of selected samples of children who have attended special clinics or been very difficult to manage and the results have been assumed to apply to most asthmatic children.

The children with continuing severe asthma at 14 years of age were the only ones in our study who showed a significantly higher incidence of behavioural disturbance compared with the controls. The correlation between behavioural disturbance and the severity of asthma (as assessed clinically and by airways obstruction measured physiologically) and the degree of allergic distrubance was highly significant. Pinkerton (1967) also showed a significant correlation between behavioural disturbance and airways obstruction measured by the degree of bronchial constriction in response to exercise. Few other studies have tried to correlate behavioural disturbance with airways obstruction measured physiologically or with the degree of allergic disturbance. Dubo et al. (1961), failed to show any correlation, but they found a highly significant correlation of behavioural disturbance with the degree of disturbance in the family. The main problem in comparing the results of the present study with those of others is that the patients in the others were not randomly selected nor objectively assessed for airways obstruction or allergic status.

It is important to note that behavioural traits such as enuresis, tics, habit spasms and stammering, and antisocial behaviour did not occur more often in severely affected asthmatic children than in the controls (see table). It might appear that a stereotype pattern of behaviour occurred in these children, but this was not so: individual children varied considerably. As many of the behavioural characteristics have already been described in highly selected samples of asthmatic children (Rogerson et al., 1935; French and Alexander, 1941; Gunnarson, 1950; Strauss, 1935; Rees, 1956; Creak and Stephens, 1958; Pinkerton, 1967) probably many of the children came from a similar section of the asthmatic population as the grade D children in our study. Our study gives no indication of the psychodynamics of the behavioural disturbance.

\section{PARENTAL ATTITUDES}

The outstanding finding was the concern of the mothers of the children in grades $C$ and $D$ to protect their health. This was not surprising, since they were the children with continuing asthma. The only other significant disturbance seen in the mother-child relationship was a conflict at meal times in the grade $\mathrm{D}$ children.

Since the patterns of behavioural disturbance in grade $D$ children resembled those described by other workers it would be expected that some of the parental attitudes described by them, other than over-protection, would have been seen in the parents of grade $\mathrm{D}$ children. There are three possible explanations for this apparent anomaiy. Firstly, that the methods used in our study were inappropriate for detecting all aspects of the motherchild relationship. Secondly, that other disturbed mother-child reiationships did occur but in only a few families-too few to be found by group analysis. Thirdly, that the mother-child relationship of over-concern was predominant and that both the child's behaviour and mother's reaction was a response to leng-continuing illness.

Ail three explanations are probably correct, for the population of farnilies with disturbed asthmatic children is probably by no means a homogenous one. Different stadies have shown a variety of parental attitudes, and clinicians are well aware of he broad spectrum of life experience and personality development in asthmatic children and their families. Specific methods may be needed to define certain aspects of the mother-child relationship.

Williams (1973) designed an experiment to test whether there was a dependency conflict in the mother-child relationship in patients from the present study. $\mathrm{He}$ assessed achievement motivation and level of aspiration in both a severe and a mild group of asthmatic children and compared them with two control groups, one of normal children the other of children with cystic fibrosis. The results showed that the asthmatic children aspired higher with greater maternal involvement and regressed more when separated from their mothers. There were significant differences when compared to the normal and fibrocystic children. It was considered that there was a greater dependency conflict in the asthmatic children and that the more severe the asthma the greater was the conflict. The asthmatic children also differed significantly from the cystic fibrosis children, suggesting that this dependency conflict, with its behavioural pattern, may be characteristic for asthma and not the result of chronic illness, as suggested by Neuhaus (1958).

\section{SOCIAL STRUCTURE OF FAMILIES}

Socioeconomic factors were unimportant in relationship to asthma. There were no differences in any of the grades of asthma or control group in social class, father's occupation, parents' ages, housing or income. Graham et al. (1967), however, found that social classes I and II were significantly overrepresented. The families of grade $\mathrm{D}$ asthmatic children were significantly larger than the families of grade A children. Dawson et al. (1969) also found that severely affected asthmatic children came from larger families.

The families of grade D children differed from the families of other asthmatic children and the control families in the way they functioned. A number of factors suggested that they were probably under stress. There was more family disruption and resentment between parents and the mothers were more often entirely responsible for the economic management of the home. These mothers also showed more anxiety in the interviews with the social workers and doctors, as judged by the physiological manifestation of flushing and by talking excessively and expressing more concern about their child. It was impossible to assess the variety of factors responsible for the stress or to determine whether the stress was a sequel of the child's severe asthma or was present beforehand.

\section{Conclusion}

Clinicians often have difficulty in relating data from population studies to the care of individual patients. Nevertheless, the significant aspects of this study serve as useful guidelines to the clinician and help broaden his perspective.

The two most important findings were that behavioural disturbances were commoner only in the small group of severely affected patients compared to the control group and that there was a significant correlation between severe ventilatory impairment and emotional disturbance. The implications of these findings are clear. Patients with severe ventilatory disturbance should be assessed psychologically and the family interrelationships assessed. Conversely, patients whose asthma is considered to be primarily due to emotional disturbance should never be treated without adequate physiological assessment, since they oftei hive severe airways obstruction and pharmacological treatment is as essential for them as psychological help. While clinicians should appreciaie the significant correlation between emotional and ventilatory disturbance it is by no means invariable or exciusive. For example, a child with mild episodic asthma and ririmal airways obstruction may be emotionally 
disturbed, while a child with a severe ventilatory defect may have minimal emotional disturbance.

The design of this study was such that only limited answers could be given to some of the questions asked. The methodology aimed to reduce complex aspects of personality behaviour and family relations to simple reproducible parameters that could be objectively scored on digital coding scales. The advantages and limitations are obvious. When significant differences were found the observations were almost certainly valid but the cut-off points may have been too rigid, so that a complete range of behavioural disturbances and relationships were not revealed. Whether behavioural disturbances were specific to asthma, whether they were consequent on asthma or preceded its development, or whether they were the result of disturbed family relations are important questions which remain unanswered. They will be answered only by specifically designed prospective studies in which asthmatic and control samples of both normal children and children with chronic illness will be randomly selected and the clinical, physiological, and allergic aspects of the asthmatic samples clearly defined.

This study was supported by a grant from the Asthma Foundation of Victoria.

\section{References}

Alcock, T. (1960). British fournal of Medical Psychology, 33, 133. Creak, M., and Stephens, J. M. (1958). Pediatric Clinics of North America, 5,731 .

Dawson, B., Horabin, G., Illsley, R., and Mitchell, R. (1969). Lancet, 1, 827. Dubo, S., et al. (1961). Fournal of Pediatrics, 59, 402.

Feingold, B. F., Singer, M. T., Freeman, E. H., and Deskins, A. (1966). fournal of Allergy, 38, 143.

Freeman, E. H., Feingold, B. F., Schlesinger, K., and Gorman, F. J. (1964). Psychosomatic Medicine, 26, 543.

French, T. M., and Alexander, F. (1941). Psychosomatic Medicine; Monograph Series $(I V)$. National Research Council, Washington D.C.

Graham, P. J., Rutter, M. L., Yule, W., and Pless, I. B. (1967). British Fournal of Preventive and Social Medicine, 21, 78.

Gunnarson, S. (1950). International Archives of Allergy and Applied Im-

munology, 1, 103.
McNicol, K. N., and Williams, H. E. (1973 a). British Medical fournal, $4,7$.

McNicol, K. N., and Williams, H. E. (1973 b). British Medical fournal, 4,12 .

Mansmann, J. A. (1952). Annals of Allergy, 10, 583.

Miller, H., and Baruch, D. W. (1948). Psychosomatic Medicine, 10, 275.

Neuhaus, E. C. (1958). Psychosomatic Medicine, 20, 181.

Pinkerton, P. (1967). Journal of Psychosomatic Research, 11, 11.

Rees, L. (1956). Fournal of Psychosomatic Research, 1, 212.

Rogerson, C. H., Hardcastle, D. H., and Duguid, K. (1935). Guy's Hospital Reports, 85, 289 .

Strauss, E. B. (1935). Guy's Hospital Reports, 85, 309.

Williams, H. E., and McNicol, K. N. (1969). British Medical fournal, 4, 321.

Williams, J. S. (1973). Fournal of Child Psychology and Psychiatry and Allied Disciplines. In press.

\title{
Area Differences in Spontaneous Abortion Rates in South Wales and Their Relation to Neural Tube Defect Incidence
}

\author{
C. J. ROBERTS, SETSUKO LLOYD
}

British Medical fournal, 1973, 4, 20-22

\section{Summary}

Data are presented from the South Wales Congenital Malformation Survey (92,982 births 1964-6 inclusive) showing that within areas in South Wales there exists an inverse relation between previous spontaneous abortion rate and the prevalence at birth of neural tube defect (anencephaly or spina bifida cystica or both). This relation is independent of social class, parity, and maternal age, and is not likely to be explained by area differences in accuracy of reporting previous spontaneous abortions.

On the basis of these findings a hypothesis is advanced which proposes that the incidence of neural tube defects is uniform throughout South Wales and that the present substantial and relatively stable differences in area prevalence are controlled by small area differences in mortality of malformed embryos. This would seem to suggest that factors initiating the malformation are genetic and that any related environmental factors exert their effect on already abnormal fetuses by influencing, in one way or another, their capacity to survive.

\section{Introduction}

Support for the view that environment is an important factor in

\footnotetext{
Department of Social and Occupational Medicine, Welsh National School of Medicine, Cardiff CF4 4XN C. J. ROBERTS, PH.D., M.D., Senior Lecturer SETSUKO LLOYD, B.SC., Scientific Officer
}

the aetiology of neural tube defect (anencephaly or spina bifida cystica or both) derives from the epidemiological finding of an association between neural tube defect incidence on the one hand and variables such as parity, social class, season, and place of birth on the other. "Incidence" in this context is used loosely when what is in fact described is "prevalence" at the time of birth. The critical issue when making inferences on aetiology is the extent to which prevalence at birth is an accurate reflection of incidence in early pregnancy, or as Lowe (1972) picturesquely put it, the extent to which "what comes down at birth is a guide to what went up at conception."

Observed differences of prevalence at birth, then, can be the result of differences in incidence in early pregnancy, differences in malformed embryonic mortality, or both. When two populations are compared it follows that the use of birth prevalence of neutral tube defects as an index of incidence in early pregnancy can be justified only if it is assumed that malformed embryonic mortality rates are the same for each population.

We present evidence from the South Wales Congenital Malformation Study which suggests that malformed embryonic mortality rates are not constant from one area population to another, and we discuss the implications this has for making inferences on differences in neural tube defect incidence.

\section{Sources of Data}

For three years beginning 1 January 1964 information was collected about all infants born to women resident in South Wales and about all the congenital defects identified in that birth population (Richards and Lowe, 1971). The survey area comprised two counties (Glamorgan and Monmouthshire) and the four county boroughs within their boundaries (Cardiff, Swansea, Merthyr Tydfil, and Newport). In the three years of the investigation 92,982 infants (live and stillbirth) were born to women resident in the area. Of these infants 90,921 were the 